\title{
The Effect of Using an Electronic Instructional Game in Improving English Language Vocabulary for Third Graders in Irbid City
}

\author{
https://doi.org/10.3991/ijim.v11i6.7417 \\ W. Alsharafat $\left({ }^{\varpi}\right)$ \\ Al al-Bayt University, Mafraq, Jordan \\ wafawork@yahoo.com \\ Wesam Kudri Alrashdan \\ Al- Balqa' Applied University, Irbid, Jordan \\ Mohammad Bani Younes \\ Al al-Bayt University, Mafraq, Jordan
}

\begin{abstract}
This study aims to investigate the effect of using an educational computer game on the improvement of learning English language vocabulary in the city of Irbid. To achieve this aim was programmed a computer game to teach third graders English language vocabulary. The sample of the study consisted of 97 male and female students. They deliberately selected from the Kofor Awaan Girls School and Abu Isam Primary Boys School, they were distributed over two groups: One of them is an experimental group of 52 students (male, female) taught English language vocabulary through a computer game strategy, and the other a control group of 47 students (male, female). The findings of the study showed that there are statistical significant differences at the level of $(\alpha=0.05)$ between the experimental group and the control group in favour of the experimental group, and that there are statistical significant differences at the level of $(\alpha=0.05)$ related to gender in favour of female, and that there are statistical significant differences at the level of $(\alpha=0.05)$ of the interaction between the teaching strategy and gender.
\end{abstract}

Keywords-Games, Gender, English Vocabulary.

\section{$1 \quad$ Introduction}

Technology is the basis for all fields of life, where it became an urgent necessity that cannot live in isolation in the light of information revolution, challenges and radical changes that have occurred in the global or local level since the advent of globalization so far, under the avalanche of discoveries and the expansion of markets, intensified competition among nations and others, Hence, clearly it highlights the role and importance on a personal level or the individual, the family, society and the state, 
world level in general and especially in the instructional field, such as engineering, medicine and other fields.

The instructional field has been subjected to an essential revolution as a result of the modern technology means which, in turn, led the educational institutions to race in order to provide all of the new technological means, which play a big role in helping make students learning easier and simpler, and in assisting teachers. Furthermore, it has a major role as a main source to obtain abundant information; also it is an important source in the communication process between the student and the teacher. Technology provides self-learning feature as the self-organized learning theories suppose that there is no environment guarantees for learning, as good environments for learning require changes in the selection and construction of attitudes for learning to occur [1]. It is necessary to search for ways and strategies that give the opportunity for the learner's self-learning about constructivist theory that emphasizes on active learning, which in turn encourage the independence of the learner, his initiative, research and inquiry.

Therefore, we need to learn by playing, especially the younger age categories where permeates children's educational activities that will ensure continuing education and lifelong learning, especially with the rapid technological progress.

Hence, the keen researcher in this research to provide something new to note its effect on their students through field work in education for twenty years, where the researcher noted the role of use the style of play, especially in the electronic games in the development of English words for students, and the development of attitudes towards learn the language so generated had the idea in programming easy and educational game intended for students of third grade primary modern and efficient method of active learning methods to be a model for a new start and motivate pupils to wish them learning through play and enjoy.

Some supporters add an active learning another importance is that many activities upon which this type of learning; minimize the negative learning activities such as negative listening, talking and taking notes during class time, and it is raising motivation to learn and indulge within [2].

\section{Previous Studies}

The study in [3] aimed to recognize the students' attitudes towards the use of multimedia software in English teaching material at Qatar University, has been prepared by the researcher's questionnaire to survey all respondents enrolled in a substance English constituent of the program (and taught by computer using multimedia software) the study pointed out that all the respondents have positive attitudes towards using multimedia software in English teaching material.

With regard to variable gender, the results of the study indicated that there are significant differences between the male and female responses in favor of females of the two groups. With respect to variable specialty, the study results indicated that there are significant differences between the specialization of science students and students 
of English Language in some of the questionnaire items, and there is no statistically significant difference between total degree (total) for the two groups.

Studies have indicated that the electronic games practiced by boys and girls, but many studies have shown that there are differences gendered (the social kind) in the amount of time spent and preferences each of them about the quality of these games. Also, studies have indicated were conducted in Germany the existence a gap between male and female games. $33 \%$ of females playing Game males at least once a week compared with $51 \%$ of males and $33 \%$ females playing video or computer games, compared with $54 \%$ of males. And that only $12 \%$ of female interested video games in general, compared with $36 \%$ of males [4]. Such widespread for electronic games and increased hours spent by children (male and female) at play, began to raise questions by educators, psychologists and sociologists raised about the epistemological or emotional. This became a controversial topic exists among scientists, and scholars split into two teams between optimistic for children to play electronic games and among the pessimists. Both teams have set up his point of view on the basis of arguments and assumptions that cannot be ignored with the conviction that these games will play a role in the processes of learning and teaching cognitive processes [5].

Researchers in [6] aimed to identify the effect of linguistic games and regular computerized in tackling literacy difficulties at the fourth-grade primary students compared to the usual way at two schools from private schools / Amman Governorate. The study sample consisted of 48 students were selected based on the results of the application of two tools: "Best Michael" the inflective and developer for Jordanian Environment, diagnosis and testing in the Arabic language. In this study, individuals were distributed randomly into three groups, so formed each group of 16 students, has been addressing the literacy difficulties among the first group using the linguistic computerized games, and the second group used the regular educational games, and the third group was treated in the usual way, it was designed by researchers a set of linguistic educational games after being diagnosed with literacy difficulties, and build a treatment plan, has applied lasted one month. The results of the study on the statistically significant differences in favor of students who have been treated with educational games with computerized linguistic first, and then for the benefit of students who have been treated with educational games linguistic regular second, then for the benefit of students who were treated in the usual way. The study in [6] which aimed to investigate the effect of using computerized educational games and regular indirect and delayed achievement for the students of the primary second grade / Amman Governorate in the multiplication unit mathematics compared to the traditional way. The study sample consisted of 76 female students from the primary second grade their distribution has been randomly into three groups: first learned of them, "the multiplication unit" computerized games, while the second learned the same regular material games. The third group I learned multiplication unit in the traditional manner, and it underwent three study groups for testing to measure the direct achievement of tribal and post and post deferred after the confirmation of his sincerity and persistence. The results showed that the first group that learned multiplication unit of computerized gaming was collected better, the students who learned second regular games, compared to the students who have learned the traditional way. 
Graves in [7] investigated the effect of Game Builder to increase the acquisition of learning and directions. This game requires the building of a house. And every student to participate with another colleague, each working on a separate computer, this task includes the interaction of pictorial and musical forms dedicated to writing, communication and time. Some mathematical concepts are also included. The sample size has been reached (134) students aged between (10-12 years) The results indicated that this game more than the acquisition of learning among students in the mathematics field, also pointed out that the direction towards the job and also about interacting with the colleague in the job has been improved. It was found that there are gender differences in the perception both in task or work colleague and directions [8]. Betz had conducted a study between (1996-1995) referred to in [4] and educational uses of the students Simulation games and computer simulations to enable to become more effective in solving problems. The study was conducted at New York University, using the game Sims City. The games emphasize on cooperation and accomplish the goals and include elements of architecture and urban planning, psychology, economics, political science, environmental science, mathematics, history and management. It has been designed this simulation using real world to plan and build a city conditions. The games were not revolving around the importance of winning, but about the importance of setting goals and try to achieve them. This study has shown that such games illustrate the interaction of systems as a whole, and organize and integrate complex skills and show the extent of the impact of individual actions on the systems as a whole. The study added that computer games enhance learning through experience, creativity and watch the game.

\section{$3 \quad$ Study Problem and Questions}

The words of the English language are building blocks in building language and faces many of the problems of students in the memorized it and development of the skills, so it was starting to play in the style of an educational requirement, where the student plays and learn without getting bored. Recently observed a weakness among our students in general in the field of reading and conversation, return to poverty in the outcome linguistic where of vocabulary, This is confirmed by many studies that focused on reading such as in $[9,10,11,12,13]$ which indicated the presence of weakness in reading skills among students caused by lack of the concentration of educational curricula and teaching methods to teach students the basic vocabulary of the stage of education, and non-observance of educational reading programs for individual differences, the rigidity of teaching methods and do not use modern teaching aids. Given the importance of vocabulary in general, especially in the lower main stage; and because of its role in the development of language skills, and for the a generation capable of solving the problems faced with the rapid technological advances that we have seen in our time, we identified the current study a problem to know effect of an educational game in English vocabulary development among thirdgrade primary students at Amman city ) and therefore the present study will try to answer the following questions: 


\subsection{Questions}

1. Are there significant differences at the level of significance $(\alpha=0.05)$ in the development of English vocabulary of the Third grade students due to the teaching method (electronic game / regular)?

2. Are there significant differences at the level of significance $(\alpha=0.05)$ in the development of English vocabulary of the Third grade students due to gender (male / female)?

3. Are there significant differences at the level of significance $(\alpha=0.05)$ in the development of English vocabulary of the Third grade students due to the interaction between the teaching way and the sex?

\subsection{Hypotheses}

1. There were no statistically significant differences at the level of significance $(\alpha=$ 0.05 ) in the development of English vocabulary of the Third grade students due to the teaching method (the electronic game / regular).

2. There were no statistically significant differences at the level of significance $(\alpha=$ 0.05 ) in the development of English vocabulary of the Third grade students due to gender (male / female).

3. There were no statistically significant differences at the level of significance $(\alpha=$ 0.05 ) in the development of English vocabulary of the Third grade students due to the interaction between the teaching way and the sex.

\subsection{The Study Aim}

This study aims to find out the effects of using games in improving learning English vocabulary as a foreign or second language. Many studies have shown that useful games in learning vocabulary because it supports the students' ability to memorize words, and increase their interaction as they improve their ability to contact and support the motivation. Add to that the games help teachers to create a context where useful and meaningful language are also contributing to the teachers and students directed toward a better understanding of vocabulary through educational games, and proposes a number of activities and learning techniques based on games in the classroom, hoping to attract these games educational more attention and are applied in the classroom to teach, and teach new vocabulary more effectively.

The researcher will study the application of the experimental group of males and females and two women officer's male female from the third grade students in my school Kufr Awan for girls and Obuasam School for Boys.

\subsection{The Importance Of Study}

The important current study outcomes of which may result from represented by: 
1. Definition of the strategy of teachers learning by playing and how to employ them in the school share.

2. It may contribute to the results of the current study in reducing vulnerability in learning and increase students' vocabulary.

3. Identify the modern methods of learning in the narrative is not narrative.

4. May increase the motivation of students toward learning.

5. May help solve the problem of correct pronunciation of words.

6. May provide the effort the reality on the shoulders of the teacher.

7. May contribute to this method in the style of self-learning development.

\section{The Studying Methodology}

The quasi-experimental using approach in the application of the current study, where the researcher to choose two experimental one for males and another for females and two groups two women officers, one for males and another for females, it is Primary third-grade students in my Primary School for Boys Obu asam Primary school Kufr Awan for Girls, was chosen as the two schools are deliberate for easy access to them, and to cooperate with the investigator, so the people distributed two random manner, and then the groups were subjected for pre-testing to see how rewarded before you start to apply the experience.

The sample of the study consists of a group of students distributors to two experimental one for males and another for females, and two groups two women officers, one for males and another for females, it is third-grade Primary students for the academic year 2016-2017, was chosen as the two schools are deliberate; for easy access to them, and the presence of a sufficient number of students third grade Primary at these school were the people the distribution of the random way. It was common the use of two-way analysis of variance (Two Way ANCOVA) to analyze the data and get results.

\section{$5 \quad$ Study Results}

It was the findings of the study in light of the survey questions and variables, after calculating averages, standard deviations, and processes the data statistically, as follows:

Results related to the first question:

\subsection{Results for the First question}

The first question stipulates: "Are there significant differences at the level of significance $(\alpha=0.05)$ in the English vocabulary development of the Third grade attributed to the method of teaching students (electronic game / regular)?

To answer this question was extracted arithmetic averages and standard deviations for the performance of primary third-grade students - individuals the study - the Test 
of English vocabulary pre-test and posttest according to method of teaching, sex and the interaction between them and Table 1 illustrates this.

Table 1 shows that the existence of morphological differences between the averages of the two groups in the vocabulary test, and according to the variables of the group and sex, where the arithmetic average (27.92) among females in the experimental group (electronic game style), and was (22.00) in females in the control group, and reached SMA (24.19) among males in the experimental group (electronic game style), in a post-test, while the (21.84) among males in the control group in the post-test, but a statement denote statistical differences between the arithmetic average, is use the shared two-way analysis of variance (Two-way ANCOVA) and Table 2 illustrates this.

Shown in Table 3 that the average Arithmetic average the experimental group was (26.795) which is higher than the arithmetic average of the control group (21.002), and this shows that the differences were in favor of the experimental group.

To find out the effect of size the ETA square $(\eta 2)$ calculates, where the effect size was for testing English vocabulary (0.576), and thus we can say that $57.6 \%$ of the variation in the Test of English vocabulary between the experimental group and The control returns to the method of teaching (learning by using electronic game).

Table 1. Arithmetic averages and standard deviations for the two experimental groups and control group in the pretest and post test reading critic of the Third grade students.

\begin{tabular}{|l|l|c|c|c|c|}
\hline \multirow{2}{*}{ Group } & \multirow{2}{*}{ Sex } & \multicolumn{2}{c|}{ Pre-test } & \multicolumn{2}{c|}{ Post -test } \\
\cline { 3 - 6 } & & $\begin{array}{c}\text { Arithmetic } \\
\text { average }\end{array}$ & St. div. & $\begin{array}{c}\text { Arithmetic } \\
\text { average }\end{array}$ & St. div \\
\hline \multirow{2}{*}{ Experimental } & Male & 19.04 & 5.302 & 24.19 & 4.368 \\
\cline { 2 - 6 } & Female & 21.00 & 3.764 & 27.92 & 2.783 \\
\hline \multirow{2}{*}{ Controller } & Total & 19.98 & 4.688 & 25.98 & 4.114 \\
\cline { 2 - 6 } & Female & 22.12 & 5.167 & 21.84 & 4.845 \\
\hline \multirow{2}{*}{ Total } & Male & 23.00 & 2.991 & 22.00 & 2.340 \\
\cline { 2 - 6 } & Total & 22.51 & 4.315 & 21.91 & 3.895 \\
\hline
\end{tabular}

Table 2. Common two-way analysis of variance results (Two Way ANCOVA) to test the indication of differences in the English vocabulary post test between teaching and sex and the interaction between the two categories of variables method; * Statistically significant at the level of $(\alpha=0.05)$.

\begin{tabular}{|c|c|c|c|c|c|c|}
\hline Source of variation & $\sum$ squares & $\begin{array}{c}\text { Freedom } \\
\text { Degrees }\end{array}$ & $\begin{array}{l}\text { Avg. of } \\
\text { squares }\end{array}$ & $\begin{array}{l}\text { The value of } \\
\text { (P) }\end{array}$ & Stat. Sig. & $\begin{array}{c}\text { (†2) square } \\
\text { ETA }\end{array}$ \\
\hline Common variable & 803.127 & 1 & 803.127 & 135.289 & .000 & .595 \\
\hline Teaching method & 742.584 & 1 & 742.584 & 125.090 & $.000 *$ & .576 \\
\hline Gender & 24.229 & 1 & 24.229 & 4.081 & $.046^{*}$ & .042 \\
\hline Teaching way $\times$ sex & 49.036 & 1 & 49.036 & 8.260 & $.005^{*}$ & .082 \\
\hline The error & 546.147 & 92 & 5.936 & & & \\
\hline Overall & 1930.165 & 96 & & & & \\
\hline
\end{tabular}


Paper-The Effect of Using an Electronic Instructional Game in Improving English Language Vocabu...

Table 3. Arithmetic averages modified to test vocabulary according to variables of teaching and sex and the interaction between the method of teaching way and the sex (Gender)

\begin{tabular}{|c|c|c|c|}
\hline \multicolumn{4}{|c|}{ Method of teaching way } \\
\hline \multicolumn{4}{|l|}{ The group } \\
\hline The experimental & \multicolumn{2}{|c|}{26.795} & .344 \\
\hline The controller & \multicolumn{2}{|c|}{21.002} & .374 \\
\hline \multicolumn{4}{|l|}{ The sex (gender) } \\
\hline Male & \multicolumn{2}{|c|}{23.389} & .340 \\
\hline Female & \multicolumn{2}{|c|}{24.408} & .369 \\
\hline \multicolumn{4}{|c|}{ Teaching way $\times$ sex } \\
\hline \multirow{2}{*}{ The experimental } & Male & 25.569 & .484 \\
\hline & Female & 28.021 & .487 \\
\hline \multirow{2}{*}{ The controller } & Male & 21.209 & .490 \\
\hline & Female & 20.794 & .555 \\
\hline
\end{tabular}

\subsection{Results for the second question}

The second question: "Are there significant differences at the level of significance $(\alpha=0.05)$ in the English vocabulary development of the Third grade students attributed to sex (male / female)?"

To answer this question was extracted arithmetic averages and standard deviations for the performance of primary third-grade students in the Test of English vocabulary pre-test and post test variables according to sex (Gender), and Table 1 illustrates this.

In view of Table 1 reveals an virtual difference between the averages of the two sets of comparative test English posttest vocabulary, according to the sex variable, the Arithmetic average of the performance of individuals study of the male on the development of English vocabulary in experimental group scale (24.19) and in the control group (21.84) for males and females in the experimental group (27.92) and in the control group (22.00), but a statement denote statistical differences between the arithmetic averages, it was common to use two-way analysis of variance (Two-way ANCOVA) and Table 2 illustrates this.

As shown in Table 2, there are existence statistically significant differences at ( $\alpha=$ $0.05)$ attributed to the variable sex, as the value of (P) calculated (4.081), statistically and in terms of (0.046), and to learn for those who return differences were extracted arithmetic averages adjusted between the two groups according to sex variable as show in Table 3.

And Table 3 shows that the Arithmetic average the rate for males was (23.389) which is less than Arithmetic average rates for females, which amounted to (24.408), and this shows that the differences came for the benefit of females in the post-test.

To find out the effect of size the ETA square $(\eta 2)$ calculates as the effect of size was for testing English vocabulary (0.042), and thus we can say that $4.2 \%$ of the variation in the Test of English vocabulary between males and females return to sex (males and females). 
Paper-The Effect of Using an Electronic Instructional Game in Improving English Language Vocabu...

\subsection{Results for the third question:}

The third question stipulates:"Are there significant differences at the level of significance $(\alpha=0.05)$ in the English vocabulary development of the Third grade students attributed to the interaction between the teaching way and the sex?"

To answer this question was extracted arithmetic averages and standard deviations for the performance of primary third-grade students in the Test of English vocabulary according to variables of sex and teaching method, Table 1 illustrates this.

Shown in Table 2 the existence of morphological differences in the arithmetic averages in Test of English vocabulary is attributable to the interaction between teaching way and sex, to find out those to whom return differences were conducting joint two-way analysis of variance (Two way ANCOVA), as shown in Table 3.

Shown in Table 3 and no statistically significant differences at $(\alpha=0.05)$ is attributable to the interaction between teaching and sex the way, as the value of $(\mathrm{P})$ calculated (8.260), statistically and in terms of (0.05), and to learn from those to whom return differences were extracted arithmetic averages amended the interaction between the teaching way and sex, and Table 3 illustrates this.

In view of the Table 3 shows that the Arithmetic average the rate of the interaction between the experimental and control groups and sex indicates the existence of differences came in favor of females in experimental group, where the rate was Arithmetic average (28.021), while the amount of the control group (20.794), while males in the control group lost the rate was Arithmetic average (21.209), while the experimental group was (25.569), which means the existence of an interaction between sex and teaching method in favor of females.

To find out the effect of size the ETA square $(\eta 2)$ calculates as the effect of size was for testing English vocabulary (0.082) and thus can be said that $8.2 \%$ of the variance in vocabulary test is attributable to the interaction between teaching way and sex, the following figure shows the graphic interaction between teaching way and sex (Gender).

Shown in Fig. 1the existence of an interaction between teaching way and sex to test the English vocabulary and the figure shows that the interaction between males and females, in the control group was in favor of males, reaching the arithmetic average for males (21.209), and females (20.794), while in the group Experimental was in favor of females, reaching the arithmetic average for females (28.021), and males (25.569). 


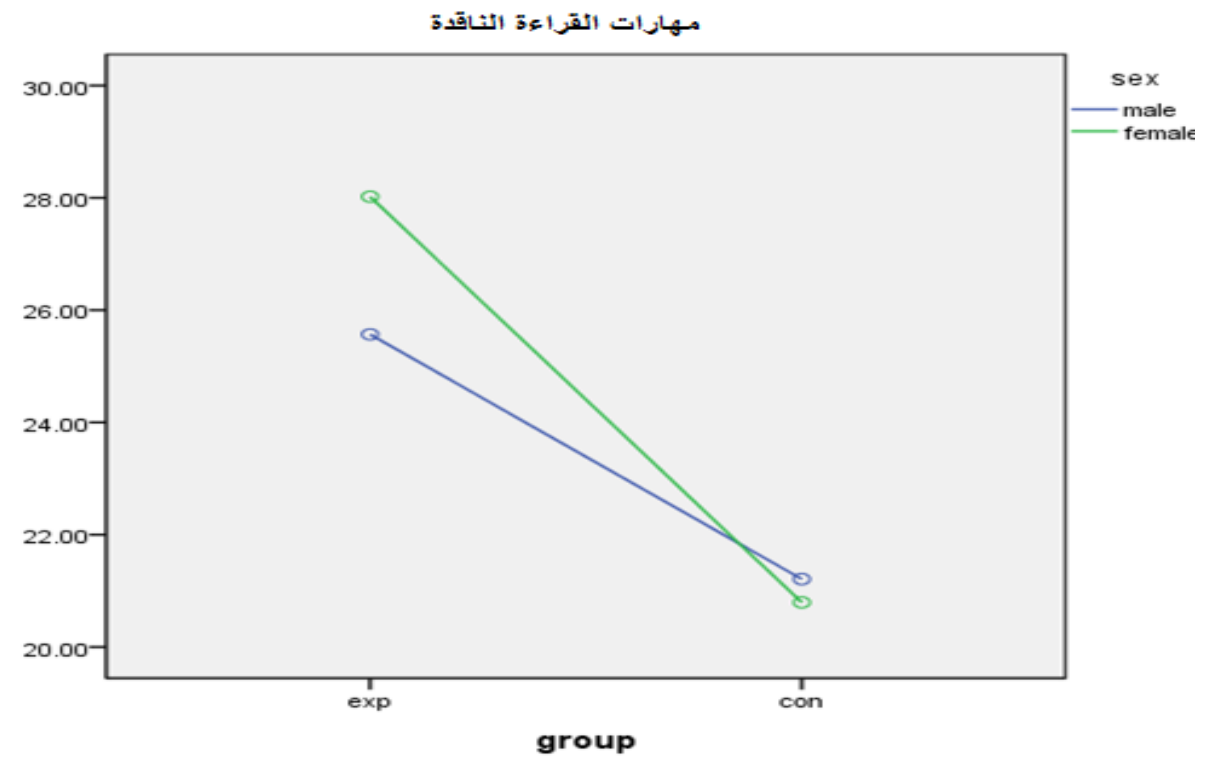

Fig. 1. Graphic interaction between teaching method and sex on the Test of English vocabulary

\section{Discussion Results}

This study sought to investigate the effect of using electronic educational game in English vocabulary development in Third grade students, and this chapter includes a discussion of the most important findings, this study, and in light of this, made a series of recommendations and proposals.

\subsection{First: Result discussion relating to the first question:}

The first question stipulates: "Are there significant differences at the level of significance $(\alpha=0.05)$ in the English vocabulary development of the Third grade attributed to a method of teaching students (learning by using electronic educational game / regular)?"

Results showed that study, and There are existence significant differences at ( $\alpha=$ 0.05 ) between the average performance of the group that studied according to the learning style using educational game electronic group that studied according to the regular method, where the rate was the arithmetic average of the group that studied according to learn using educational game style electronic test vocabulary posttest (26.795), and was Arithmetic average the rate of the group, who studied in the usual way (21.002).

This demonstrates the effectiveness of the learning method using educational game electronic in English vocabulary development among students compared to the usual way, as it is this method of teaching methods that graduated students from the nega- 
tive role in learning process of education and of being the recipient of the information, it is transmitted to the positive role it discovers information himself, and this called for in cognitive theory; making it independent of the individual thoughts, and ensures the continuity of learning for him.

This can be attributed why superiority of learning method using educational game electronic on the regular way in the development of English vocabulary to the lack of practice this method in their classrooms; raising activity and motivation as a method other than usual, which students feel with enthusiasm and positive interaction while learning vocabulary in English .

Reason superiority of learning method using educational game electronic - the regular way in teaching of English vocabulary that students themselves have felt pleasure in learning process because of diversity exciting educational electronic such as motion, colors and stimulation that increased interaction with the vocabulary and give them the proper sense of the game and the elements may be due through images that facilitate the process of representing semantic and easier than remembering and connecting mental and coding processes, particularly as they were in childhood.

The result of this study agreed with the findings of some studies, including a study (AlMannai, 2000; and Alheileh, 2005; and Alheileh and Ghoneim, 2002), which demonstrated the effectiveness of a method using electronic games in learning.

\subsection{Second: Discuss the results relating to the second question:}

The second question stipulates: "Are there significant differences at the level of significance $(\alpha=0.05)$ in the English vocabulary development of the Third grade students attributed to sex (male / female)?"

The results showed a statistically significant difference at $(\alpha=0.05)$ between the arithmetic averages of the performance of the two study groups according to sex (gender) (male and female) in post-test, where the arithmetic average the rate for males (23.389), and the arithmetic average the rate for females (24.408) in favor of females.

This demonstrates the superiority of the female performance of the male performance in the Test of English vocabulary posttest, this superiority is attributable to the students to reveal their greater interest than males in doing computerized activities and attention to the movement and colors compared to males, who are more responsible and have a desire more in the quest to prove self, thus raising the level of motivate for collection and delivery, in addition to that they are more focused when learning vocabulary in this way and in the tests.

This result agreed with some studies, including a study (AlMannai, 2000; Graeves, 20 ), which proved the existence of the effect of sex, he differed with each other, including the study of (Al Mubireek, 2003), which proved the existence of the effect of sex in favor of males. 
Paper-The Effect of Using an Electronic Instructional Game in Improving English Language Vocabu...

\subsection{Third: Discuss the results relating to the third question:}

The third question stipulates: "Are there statistically significant differences at the level of significance $(\alpha=0.05)$ in the English vocabulary development of the Third grade students attributed to the interaction between the teaching way and the sex?".

Results showed that study, and There are existence significant differences at $(\alpha=$ 0.05 ) between the average performance of experimental group that studied according to learning style using electronic educational game, and the control group, who studied in the regular manner in Test of English vocabulary, attributed to interaction between the teaching method and the sex, interaction came in favor of females in experimental group reached an arithmetic average (28.021), which is higher than the arithmetic average for males in the same group, which amounted to (25.569).

This indicates the superiority of females in the experimental group in Test of English vocabulary, which indicates that the interaction between the variables of the study had an effect on the development of this vocabulary for females in the experimental group, which means an effective learning method using educational electronic game with females, and may be the nature of the female and tendencies of movement role and colors in it.

\section{$7 \quad$ References}

[1] Zimmerman 'E. (2002). Rules of play: Game design fundamentals. Cambridge ‘MA: MIT Press.

[2] Carroll, L. \& Leander, S. (2001). Improve motivation through the Use of Active Learning Strategies. Unpublished Master Dissertation. Saint Xavier University.

[3] Mannai, Abdullah Salem, (2001), a survey of students' attitudes towards the use of multiple teaching English media software, Journal of the Islamic Educational Sciences 0.10 folder, number one, the University of Qatar, Doha.

[4] Mubireek, K. A. (2003). Gender-oriented vs. gender-neutral computer games in education. $\mathrm{PhD}$ Thesis, The Ohio State University, United States - Ohio.

[5] Al Heileh, Mohamed Mahmoud, 2005, the impact of the use of computerized games and regular in the collection of the basic second grade students in mathematics compared to the traditional way, Mutah University, Mutah University Journal for Research and Studies.

[6] Al Heileh, Mohamed Mahmoud, and Aisha Ghoneim, 2002, the impact of computerized linguistic educational games and regular in tackling literacy difficulties with the fourthgrade primary students, Najah National University magazine, the humanities, Nablus, Vol. 16, pp. 596-626.

[7] Graves, M.F., The vocabulary book: Learning an instruction, (New York: Teachers' College Press, 2006). Www.graphicsinterface.org

[8] Dhanhani, Rashid (2004). The level of critical reading in the Arabic language skills of the sixth and seventh grades in public and key pilot schools in the UAE students. Master Thesis, the University of Jordan.

[9] Abu Hija, and Khaldoun al-Saadi, Imad (2003). The impact of education and learning style model in the development of critical reading skills of fourth grade primary pupils. Damascus University Journal, 19 (1) pp.129 - 180.

[10] Jalal, Ali (2004). Over the mastery of high school students for critical reading skills. Master thesis, Yemen: Sana'a University. 
Paper-The Effect of Using an Electronic Instructional Game in Improving English Language Vocabu...

[11] Abu Alruzz, Dia (2006). Arabic language teachers practices to teach critical reading skills in the tenth grade and their impact on student achievement and attitudes toward reading. A Master Thesis, the Hashemite University.

[12] Hatamleh, Mohammed (2014). Effectiveness based on integrative oriented to the improvement of critical reading skills of basic ninth-grade students in Jordan program. Master Thesis, Oman: The University of Jordan.

\section{Authors}

W. Alsharafat is with the Prince Hussein Bin Abdullah Faculty of Information Technology at Al al-Bayt University, Mafraq, Jordan

Wesam Kudri Alrashdan is with Al- Balqa' Applied University, Irbid, Jordan.

Mohammad Bani Younes is with the Prince Hussein Bin Abdullah Faculty of Information Technology at Al al-Bayt University, Mafraq, Jordan.

Article submitted 12 July 2017. Published as resubmitted by the authors 13 September 2017. 